Sialic acid concentrations in urine and cultured fibroblasts

\begin{tabular}{|c|c|c|c|}
\hline \multirow{2}{*}{\multicolumn{2}{|c|}{ Patient }} & \multicolumn{2}{|c|}{ Controls } \\
\hline & & Mean & Range \\
\hline $\begin{array}{c}\text { Urine }(\mu \mathrm{mo} \\
\text { creatinine } \\
\text { Free } \\
\text { Bound }\end{array}$ & $\begin{array}{l}994 \\
109\end{array}$ & $\begin{array}{l}93,78 \\
71,52\end{array}$ & \\
\hline $\begin{array}{c}\text { Fibroblasts } \\
\text { protein) } \\
\text { Free } \\
\text { Bound }\end{array}$ & $\begin{array}{l}25 \\
17\end{array}$ & $\begin{array}{l}2 \cdot 6 \\
8.6\end{array}$ & $\begin{array}{l}1 \cdot 5-6 \cdot 7(n=9) \\
6 \cdot 5-10 \cdot 7(n=5)\end{array}$ \\
\hline
\end{tabular}

Sialic acid concentrations were measured by the thiobarbituric acid method ${ }^{4}$ before and after hydrolysis.

mus and a pale retina. Blood smears showed vacuolated lymphocytes, monocytes, and neutrophils. A bone marrow specimen also showed vacuolated cells and an excess of eosinophils. The free sialic acid concentration of cultured fibroblasts and urine was raised (table), and a diagnosis of severe infantile sialic acid storage disease was made.

Subsequent clinical progress was poor. She remained extremely hypotonic and was socially unresponsive. Oxygen requirement persisted, and she eventually died with bronchopneumonia at 13 months. Permission for necropsy was refused.

\section{Discussion}

Stevenson et al described two unrelated cases of severe infantile sialic acid storage disease and reviewed five other cases in $1983 .{ }^{4}$ The main features he identified were coarse facies, growth delay, appreciable mental retardation, hepatosplenomegaly, recurrent pneumonias, and in five, evidence of lysosomal storage with raised free sialic acid in cells and urine. The infant reported here displayed all these features, and she also showed a more pronounced respiratory impairment. Cardiac failure was also prominent, suggesting either a storage disorder of the myocardium, or a response to the respiratory problems. The presence of multiple widespread telangiectasias, presumably related to liver disease, is also a new finding.

The exact role of sialic acid in cellular function is unclear, but it is known to be an important constituent of many glycolipids and glycoproteins. It has been suggested that the underlying defect is impaired transport of free sialic acid across the lysosomal membranes, but the precise defect has yet to be identified. ${ }^{5}$ Antenatal diagnosis is available by assaying free sialic acid in amniotic fluid or by chorionic villus biopsy. $^{6}$ Severe infantile sialic acid storage disease should be considered in a child presenting with coarse facial features, growth and developmental delay, hepatosplenomegaly, and evidence of abnormal storage in cells.

We are grateful to Dr AW Boon for allowing us to report his patient.

1 Lowden JA, O'Brien JS. Sialidosis: a review of human neuraminidase deficiency. Am 7 Hum Genet 1979;31:1-18.

Aula P, Autio S, Raivio KO, et al. Salla disease - a new lysosomal storage disorder. Arch Neurol 1979;36:88-94.

Wilcken B, Don N, Greenaway R, et al. Sialuria: a second case. F Inherited Metab Dis 1987;10:97-102.

4 Stevenson RE, Lubinsky M, Taylor HA, et al. Sialic acid storage disease with sialuria: clinical and biochemical feastorage disease with sialuria: clinical and biochemical features in the severe infantile type. Pediatrics 1983;72:441-9. defect underlying the lysosomal storage of sialic acid in defect underlying the lysosomal storage of siali

6 Lake BD, Young EP, Nicholaides K. Prenatal diagnosis of Lake BD, Young EP, Nicholaides K. Prenatal diagnosis of
infantile sialic acid storage disease in a twin pregnancy. $\mathcal{f}$ Inherited Metab Dis 1989;12:152-6.
King's College School of Medicine and Dentistry, London Department of Immunology N Hadžić E T Davies

Liver Unit

B Portmann

Department of Child Health A P Mowat G Mieli-Vergani Correspondence to: Dr G Mieli-Vergani, Department of Child Health King's College Hospital, London SE5 8RX.

Accepted 5 October 1989

\title{
Acute liver failure induced by carbamazepine
}

\author{
N Hadžić, B Portmann, E T Davies, A P Mowat, G Mieli-Vergani
}

\begin{abstract}
Two children developed acute liver failure while taking carbamazepine. Clinical and laboratory findings suggested an immunoallergic reaction, but only one child improved on steroids. Determination of liver function during the first few weeks of treatment and early detection of signs of idiosyncrasy may prevent this rare but severe complication.
\end{abstract}

Since 1970, 14.5 million adults and children are estimated to have taken carbamazepine. Unwanted effects mainly or exclusively affecting the liver have been reported in 499 instances, but often other causes of liver damage were not excluded. In about half of these cases alteration in the results of liver function tests was the only abnormality reported (Ciba-Geigy, personal communication). There have been 17 deaths from liver disease, five in children, ${ }^{12}$ but in only one of these was carbamazepine the sole hepatotoxin. We describe two children receiving carbamazepine who developed life threatening liver disease.

\section{Case reports}

CASE 1

A girl aged 11.6 years developed a severe maculopapular rash, intermittent fever, arthralgia, cough, anaemia, anorexia, diarrhoea, and vomiting four weeks after starting carbamazepine ( $16 \mathrm{mg} / \mathrm{kg} / 24$ hours) for focal epilepsy. Her medical history was negative. Carbamazepine was stopped, the blood concentration being 32 $\mu \mathrm{mol} / \mathrm{l}$ (therapeutic range: $16-50 \mu \mathrm{mol} / \mathrm{l}$ ). Two weeks later she developed jaundice. On admission, six days later, she was pale and jaundiced, with a generalised exfoliative rash, periorbital oedema, generalised lymphadenopathy, and stomatitis. Firm liver and spleen 
edges were palpable 6 and $7 \mathrm{~cm}$ below the costal margin. Temperature was $38.5^{\circ} \mathrm{C}$. Her haemoglobin concentration was $76 \mathrm{~g} / \mathrm{l}$; red cell indices, reticulocyte, white cell, platelet, and differential counts were normal, with no eosinophilia; prothrombin time was 20 seconds (control 13 seconds).

Biochemical investigations were as follows (reference range in parentheses). Total bilirubin concentration was $212 \mu \mathrm{mol} / \mathrm{l}(<20)$ with a conjugated fraction of 198. Activities of enzymes were: aspartate aminotransferase $165 \mathrm{IU} / \mathrm{l}$ $(<50) ; \gamma$ glutamyl transpeptidase 299 IU/l $(<50)$; and alkaline phosphatase $407 \mathrm{IU} / 1$ $(<300)$. Albumin concentration was $31 \mathrm{~g} / \mathrm{l}$ (35-50) and concentrations of plasma sodium and proteins were normal. Concentration of $\operatorname{IgA}$ was normal but IgG, IgM, and IgE were increased $(22 \cdot 3 \mathrm{~g} / 1,5 \mathrm{~g} / \mathrm{l}$, and $30 \mathrm{kU} / \mathrm{l}(<18$, $<2 \cdot 2$, and $<10$ ) respectively). $\mathrm{C} 3$ and $\mathrm{C} 4 \mathrm{com}$ plement components were decreased $(0.35 \mathrm{~g} / 1$ and $0.13 \mathrm{~g} / 1(0.55-1 \cdot 2$ and $0 \cdot 20-0 \cdot 60)$ respectively). Autoantibodies were negative. A ${ }^{99 \mathrm{~m}} \mathrm{Tc}$ colloid liver scan showed reduced liver uptake, with increased bone and spleen uptake. Bone
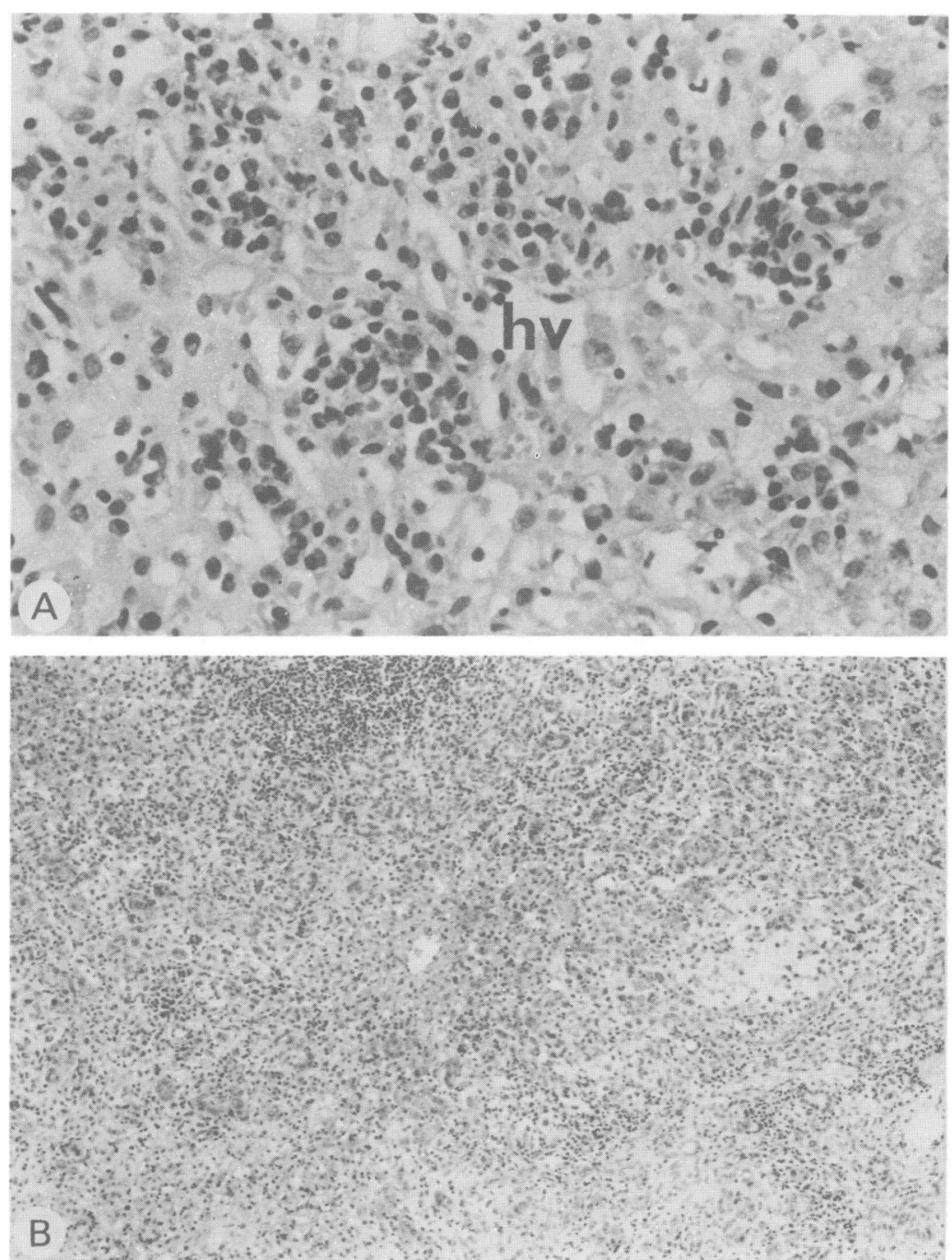

Figure 1 Liver histology. A: section from case 1 showing prominent perivenular cell loss and plasma cell infiltration ( $h v$, hepatic vennule). B: section from case 2 showing submassive parenchymal loss with widespread inflammation, scattered bile duct like structures, and only occasional islands of surviving, pale staining hepatocytes. Haemotoxylin and eosin stain: $A \times 180, B \times 45$.

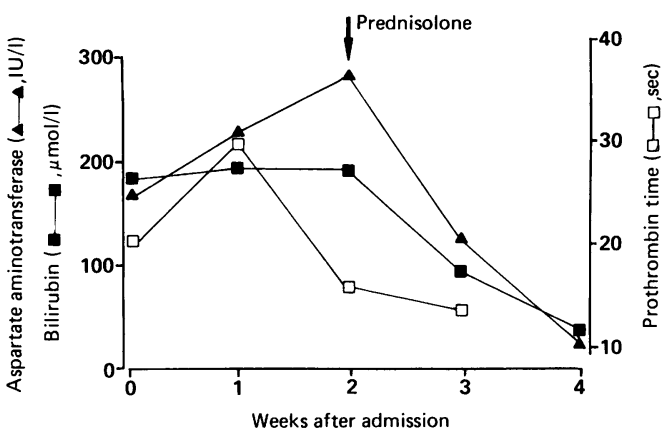

Figure 2 Effect of prednisolone treatment on serum aminotransferase, bilirubin, and prothrombin time in case 1 .

marrow aspirate contained many plasmocytoid lymphocytes and moderate erythrophagocytosis by macrophages. A specimen taken at liver biopsy, performed 12 days after admission, showed an acute hepatitis, with both portal and parenchymal cell infiltrates rich in plasma cells (fig 1A). After 10 days of supportive treatment (blood and albumin transfusions, oral iron, Ketovite (Paines and Byrne), and intravenous vitamin $\mathrm{K}$ ) without improvement, she was given prednisolone $(0.7 \mathrm{mg} / \mathrm{kg} / 24$ hours $)$. This was followed by a dramatic symptomatic and biochemical improvement, although the prothrombin time had already returned to normal before starting steroid treatment (fig 2). She was discharged one week later after complete resolution of symptoms. Her serum bilirubin concentration was $31 \mu \mathrm{mol} / \mathrm{l}, \gamma$ glutamyl transpeptidase $214 \mathrm{IU} / \mathrm{l}$, and aspartate aminotransferase, alkaline phosphatase, albumin, and prothrombin time were normal. Prednisolone was stopped after 18 days. Three years later the girl is well with normal liver function.

\section{CASE 2}

A girl aged $7 \cdot 8$ years presented with fever, generalised maculopapular rash, arthralgia, and lymphadenopathy four weeks after starting carbamazepine $(16.5 \mathrm{mg} / \mathrm{kg} / 24$ hours $)$. Seventeen days later she developed jaundice, ascites, and generalised oedema. She had had convulsions from the age of 8 months. At 3 years grand mal epilepsy was diagnosed. She received sodium valproate for two months at the age of 7 years, but she had been on no anticonvulsant treatment for four months before starting carbamazepine. On admission she was jaundiced, with generalised peeling maculopapular rash, oedema, and ascites. A firm liver was palpable $3 \mathrm{~cm}$ below the costal margin; her spleen was not palpable.

Concentrations of carbamazepine in the blood was $28 \mu \mathrm{mol} / 1$. Her haemoglobin concentration was $105 \mathrm{~g} / \mathrm{l}$ with normal white cell, platelet, and differential counts; there was no eosinophilia, and the prothrombin time was 24 seconds (control 15 seconds). Total bilirubin concentration was $236 \mu \mathrm{mol} / \mathrm{l}$ and activities of aspartate aminotransferase 946 IU/l, $\gamma$ glutamyl transpeptidase $206 \mathrm{IU} / \mathrm{l}$, and alkaline phosphatase $151 \mathrm{IU} / \mathrm{l}$. Ammonia was $94 \mu \mathrm{mol} / \mathrm{l}(10-47)$, total protein $43 \mathrm{~g} / \mathrm{l}$, albumin $24 \mathrm{~g} / \mathrm{l}$, and plasma sodium $126 \mu \mathrm{mol} / \mathrm{l}$. IgG was $5.9 \mathrm{~g} / \mathrm{l}(6 \cdot 5-18)$, 
IgA and IgM were normal, and IgE was raised at $550 \mathrm{kU} / 1$. Autoantibodies were negative. $\mathrm{C} 3$ and $\mathrm{C} 4$ were 1.5 and $0.19 \mathrm{~g} / \mathrm{l}$. She was treated with fluid restriction, vitamin $\mathrm{K}$, cimetidine, albumin and, three days after admission, prednisolone $1 \mathrm{mg} / \mathrm{kg} / 24$ hours. Four days after admission grade III hepatic encephalopathy developed and prothrombin time lengthened to 70 seconds. Because of further deterioration, orthotopic liver transplantation was performed 24 hours later when prothrombin time was 120 seconds. The excised liver was shrunken with evidence of submassive necrosis. On histology there was widespread inflammation comprised of lymphocytes, pigmented macrophages, neutrophils, and fewer plasma cells (fig 1B). The child died of infectious complications three months after transplant.

In both cases hepatitis $\mathrm{A}$ and $\mathrm{B}$, cytomegalovirus, Epstein-Barr, measles, and leptospira infections were excluded; $\alpha_{1}$ antitrypsin phenotype and caeruloplasmin, plasma and urine copper, serum potassium, calcium, phosphate, glucose, cholesterol, creatinine, and urea concentrations, and urinalysis were normal.

\section{Discussion}

The diagnosis of liver injury induced by drugs rests on the exclusion of other aetiological factors. In the two children described no other cause of liver damage or drug exposure could be identified.

Hepatic side effects of carbamazepine are very rare. Among them, changes in results of liver function tests, jaundice, and granulomatous or cholestatic hepatitis are the most common. ${ }^{3}$ In a study of children, a clinically insignificant rise in results of liver function tests was found in $6 \%$ of 220 patients. ${ }^{4}$ We have identified only three reported cases of fatal acute liver failure directly attributable to carbamazepine, one being a child. ${ }^{1}$ Recently four children with fatal fulminant hepatitis while on carbamazepine were reported. ${ }^{2}$ All were taking several drugs, with three receiving other potentially hepatotoxic drugs, such as phenytoin and pri- midone. The mechanism of liver injury in carbamazepine hepatitis remains poorly understood, although it is presumed to be an idiosyncratic hypersensitivity, ${ }^{5}$ possibly deriving from genetically determined inability to inactivate toxic metabolites. ${ }^{6}$ Consistent with reports from other authors, we found that clinical presentation and laboratory tests in our two patients suggest an immunoallergic mechanism. Thus both had onset of symptoms four weeks after starting treatment, fever, rash, arthralgia, and raised IgE with carbamazepine concentrations within the therapeutic range. In addition, case 1 had a heavy plasma cell infiltrate found on histology, decreased complement concentration with increased IgG and $\operatorname{IgM}$, and her recovery has been aided by the administration of steroids. In case 2 these features were absent and no response to steroid was observed, possibly suggesting another mode of hepatocyte injury.

Liver function tests performed routinely in the first weeks of carbamazepine treatment, and in the presence of other idiosyncratic reactions to the drug, may help to detect patients at risk of developing this rare complication.

We thank Dr TK Hanid and Dr DM Cook for referring the patients. NH is a Bristish Council Research Fellow, GMV is supported by the M McGough Foundation Against Liver Disease in Children.

1 Zucker P, Daum F, Cohen MI. Fatal carbamazepine hepatitis. 7 Pediatr 1977;91:667-8.

2 Smith DW, Cullity GJ, Siberstein EP. Fatal hepatic necrosis associated with multiple anticonvulsant therapy. Aust $N Z \mathcal{F}$

Med 1988;18:575-81.
3 Horowitz S, Patwardhan R, Marcus E. Hepatotoxic reactions associated with carbamazepine therapy. Epilepsia 1988; 29:149-54.

4 Pellock JM. Carbamazepine side effects in children and adults. Epilepsia 1987;28(suppl 3):S64-70.

5 Stricker BHC. Hepatic injury by drugs and environmental toxins. In: Arias IM, Frenkel M, Wilson JHP, eds. The liver annual/6. Amsterdam: Elsevier, 1987:538-92.

6 Shear NH, Spielberg SP. Anticonvulsant hypersensitivity syndrome. In vitro assessment of risk. 7 Clin Invest 1988;82:1826-32.

\section{Addendum}

Since this paper was accepted we have admitted and successfully transplanted a 3 year old child who had fulminant hepatic failure due to carbamazepine toxicity.

\title{
Contractural arachnodactyly with mitral regurgitation and iridodonesis
}

\author{
I C Huggon, J P Burke, J F Talbot
}

Paediatric Unit,

\section{Northern General}

Hospital

I C Huggon

Department of Ophthalmology, Royal Hallamshire Hospital, Sheffield

J P Burke

J F Talbot

Correspondence to: Correspondence to:
Mr J P Burke, Department of Ophthalmology, Royal Hallamshire Hospital,
Sheffield S10 2JF.

Accepted 9 October 1989

\begin{abstract}
An infant girl with arachnodactyly, spontaneously resolving contractures, dolichostenomelia, iridodonesis, and mitral and tricuspid incompetence died in cardiac failure. We confirm that congenital contractural arachnodactyly may exhibit serious cardiovascular and ophthalmic complications like Marfan's syndrome. The presence of iridodonesis further obscures the differentation between classical Marfan's syndrome and congenital contractural arachnodactyly.
\end{abstract}

Beals and Hecht described an autosomal dominant syndrome of congenital contractural arachnodactyly distinct from classical Marfan's syndrome. ${ }^{1}$ It is characterised by multiple contractures at birth that resolve spontaneously (in 94\%), dolichostenomelia, arachnodactyly (in $85 \%$ ), abnormalities of the external ears (in $65 \%),{ }^{2}$ and the absence of the eye and cardiovascular abnormalities typical of Marfan's syndrome. Since then, however, serious eye and cardiac abnormalities that lessen the distinction from Marfan's syndrome have been described. ${ }^{3-5}$ 